\title{
ASO Visual Abstract: Mesopancreas Excision and Triangle Operation During Robotic Pancreatoduodenectomy
}

Marcel Autran Machado, MD, FACS, Bruno V. Mattos, MD, Murillo Macedo Lobo Filho, MD, and Fabio Makdissi, MD

Nove de Julho Hospital, São Paulo, Brazil

Robotic pancreatoduodenectomy was performed at the authors' center for 87 patients between March 2018 and March 2021 (https://doi.org/10.1245/s10434-021-10412-4). For 22 of these patients, robotic mesopancreas excision was performed. The robotic total mesopancreas excision and the Triangle operation are feasible and safe for selected patients. The indications for this radical operation are a high risk for $\mathrm{R} 1$ resection and locally advanced disease.

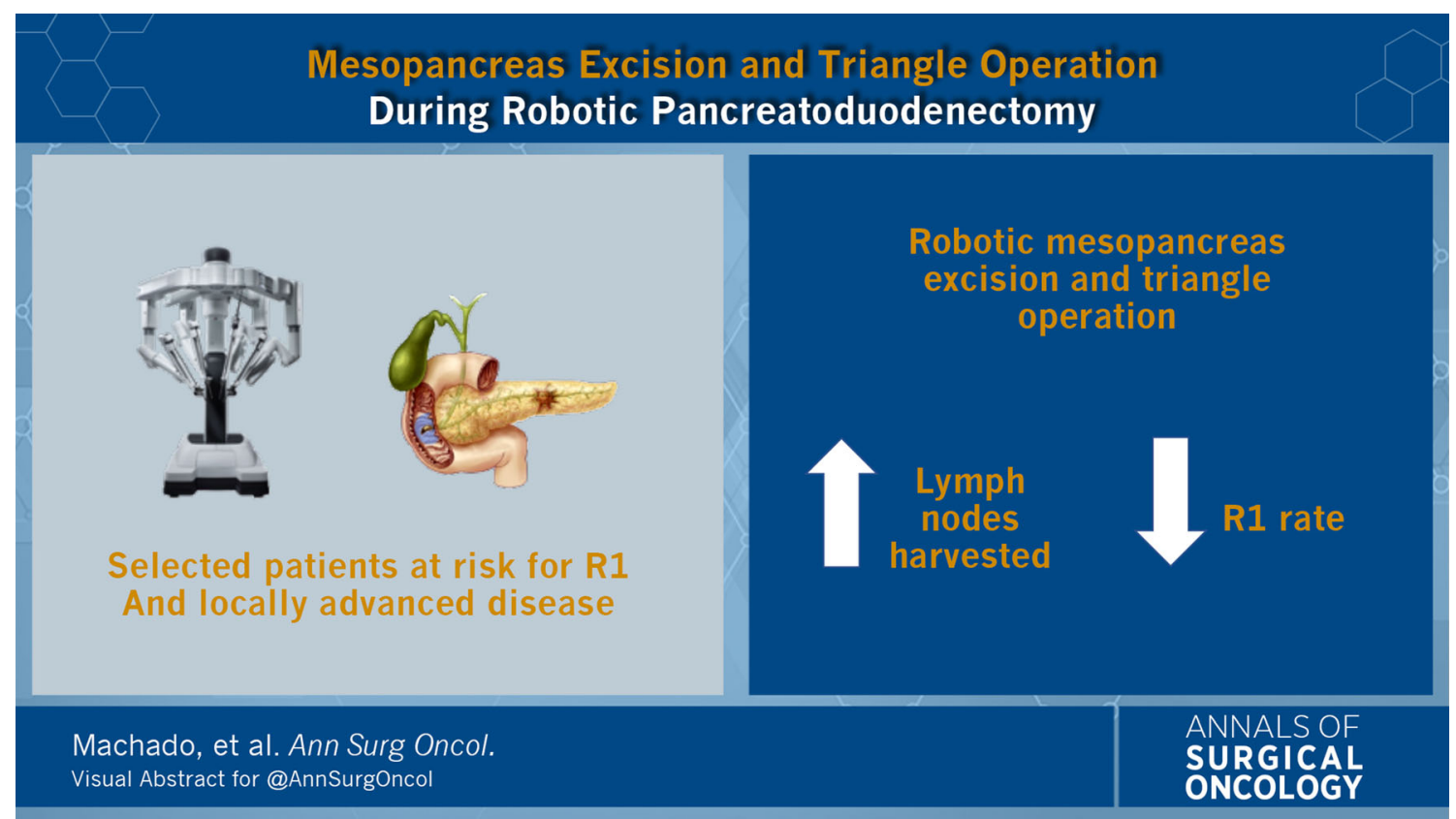

(C) Society of Surgical Oncology 2021

Published Online: 23 July 2021

M. A. Machado, MD, FACS

e-mail: dr@drmarcel.com.br

Publisher's Note Springer Nature remains neutral with regard to jurisdictional claims in published maps and institutional affiliations. 